\title{
O ambiente e as inter-relações do paciente internado com doença infecto-contagiosa
}

\author{
Carmen Gasparin*, Ana Maria Dyniewicz, D.Sc.**, Luísa Canestraro Kalinowski***
}

*Psicóloga, Curso de Pós-Graduação Gestão em Saúde Pública pela Pós-Graduação Bagozzi, Curitiba/PR, **Membro do Grupo de Pesquisas em Políticas, Gestão e Práticas em Saúde, Universidade Federal do Paraná (UFPR), Curitiba, ***Acadêmica de Enfermagem da UFPR, Bolsista de Iniciação Cientifica PIBIC/CNPq

\section{Resumo}

Este estudo descritivo-exploratório objetivou identificar o ambiente e as inter-relaçóes de portadores de doenças infectocontagiosas. Foi realizado por meio de entrevista com 15 questôes, entre fevereiro e março de 2009, com 42 pacientes na cidade de Curitiba/PR. Nos resultados destacam-se: o atendimento na admissáo foi considerado ótimo para 60\% dos entrevistados; 98\% se sentem acolhidos; $67 \%$ consideram ótimo o conforto nas enfermarias; $80 \%$ consideram ótimas as refeiçóes e roupas de uso hospitalar; para 38\% os médicos são os que menos esclarecem suas dúvidas; para $43 \%$ os profissionais demonstram mau humor e 57\% permanecem no leito a maior parte do tempo. Conclui-se que há necessidade de melhorias no relacionamento com a equipe de saúde. Para os pacientes há tempo ocioso e isto afeta sua recuperaçáo. Sugere-se que açóes educativas e lúdicas sejam implementadas na instituiçáo.

Palavras-chave: hospitalização, doenças transmissíveis, humanização da assistência.

\section{Abstract \\ The environment and interrelationships of the hospitalized patient with contagious diseases}

This is a descriptive-exploratory study aiming at identifying environmental situations and interrelationships of patients with contagious diseases. It was carried out by means of a 15 questions interview with 42 patients in the city of Curitiba/PR on 2009 February and March. It can be pointed out among the results: admission service was considered excellent by $60 \%$ of the patients; $98 \%$ felt welcome; $67 \%$ considered wards very comfortable; $80 \%$ found meals and hospital clothing excellent; $38 \%$ thought that doctors do not clear their doubts; for $43 \%$ the professionals expressed their bad mood and $57 \%$ staid in their beds most of the time. It is concluded that there should be an improved relationship between patient and health team. For patients, there has been too much empty time which affects their recovery. It is suggested more educational and playful actions in the institution.

Key-words: hospitalization, communicable diseases, humanization of assistance. 


\section{Resumen}

\section{El ambiente y las interrelaciones del paciente internado con enfermedad infectocontagiosa}

Es una investigación descriptiva y exploratoria que tuvo el objetivo de identificar el ambiente y las interrelaciones personales de portadores de enfermedad infectocontagiosas. Fue realizada a través de entrevista con 15 preguntas, entre Febrero y Marzo de 2009, con 42 pacientes en la ciudad de Curitiba, Paraná. En los resultados, se destacan: el servicio de admisión fue considerado óptimo para $60 \%$ de los entrevistados; $98 \%$ se sienten acogidos; $67 \%$ consideran óptimo el confort en las enfermerías; $80 \%$ consideran óptimas las comidas y ropas del hospital; para 38\%, los médicos son los que menos aclaran sus dudas; $43 \%$ de los profesionales demuestran malhumor y $57 \%$ permanecen en la cama la mayor parte del tiempo. Se concluyó que hay necesidad de introducir mejoras en la relación con el equipo de salud. Para los pacientes, hay tiempo ocioso, lo que afecta su recuperación. La sugerencia es que haya mayor interacción y que acciones educativas y lúdicas sean implementadas en la institución.

Palabras-clave: hospitalización, enfermedades transmisibles, humanización de la atención.

\section{Introdução}

Diante da complexidade das relaçóes entre saúde e doença e da dinâmica das instituiçóes de saúde, uma questáo importante é reconhecer o sofrimento do indivíduo internado além da sua dor física e acolhê-lo para dar sentido ao resgate da saúde integral [1].

Para isso existem diversas estratégias, como o Programa de Humanização da Assistência Hospitalar (PNHAH) do Ministério da Saúde, que preconiza oferecer oportunidades de saúde às pessoas, indo além de tratar a doença por meio de medicamentos, exames e intervenção técnica; mas vendo o paciente como um todo, atentando, inclusive, para os fatores estressores que estão interferindo na sua recuperação, durante o período da internação hospitalar [2].

Este programa propóe ainda um conjunto de açóes integradas que visam mudar substancialmente o padrão de assistência ao usuário nos hospitais públicos do Brasil, melhorando a qualidade e a eficácia dos serviços hoje prestados por essas instituiçóes, além de buscar aprimorar as relaçóes entre profissionais de saúde e usuário; as relaçóes dos profissionais entre si e do hospital com a comunidade [3]. Uma equipe de saúde despreparada e em desacordo quanto à compreensáo dos aspectos emocionais dos pacientes pode acarretar sérios danos ao doente, retardando a sua recuperação [4].

Afinal, perceber o outro requer atitude profundamente humana [5]. Reconhecer e promover a humanização demanda esforço para rever atitudes e comportamentos dos profissionais envolvidos direta ou indiretamente com o cuidado do paciente. Assim, a humanização supóe troca de saberes, diálogo entre os profissionais e modelo de trabalho em equipes interdisciplinares, sustentando a produção em grupo.

O presente estudo investigará o acolhimento, a ambiência, e a atenção especializada oferecidos ao portador de doença infecto-contagiosa, internado em hospital. Especificamente, tem como objetivo analisar o ambiente hospitalar e as inter-relações com a equipe de saúde, com os quais convivem estes pacientes.

Justifica-se o estudo pela valorização de abordagem integral da saúde, a qual requer que os profissionais revejam suas atitudes e concepçóes, excessivamente centradas em um enfoque biomédico.

No caso de doenças infecto-contagiosas o trabalho da equipe multiprofissional ainda se apresenta com respostas de caráter informal, dependentes de iniciativas de cunho pessoal e motivadas por sentimentos compassivos. Requer avanços no diálogo, que garanta e estimule uma crescente integração entre as finalidades técnicas do trabalho e os projetos de vida dos usuários. Projetos de açáo de equipe assumidos enquanto processos de construçáo dinâmica, coletiva e participativa que supóem estabelecer um ambiente de cuidado humano, uma cultura de respeito e valorização não da doença, mas do ser humano que adoece e do ser humano que cuida, contemplando uma relação sujeito-sujeito e não sujeito-objeto $[6,7]$.

Convém destacar, por fim, que o cenário da atenção ao indivíduo doente mudou em 1988, com a implantação do Sistema Único de Saúde (SUS), direcionado para o direito à saúde de toda a população por meio de políticas públicas. A partir de então, novas estratégias surgiram para aperfeiçoar $o$ atendimento às necessidades do usuário, ou seja, humanizar a assistência à saúde. 


\section{Material e métodos}

Foi realizada pesquisa descritiva e exploratória, utilizando formulário semi-estruturado com questôes abertas e fechadas, aplicado individualmente a pacientes de ambos os sexos, internados em um hospital da cidade de Curitiba, estado do Paraná, independente da faixa etária e Código Internacional de Doenças (CID), com no mínimo cinco dias de internação e em condiçóes cognitivas. Os sujeitos que aceitaram participar da pesquisa assinaram o termo de consentimento livre e esclarecido. Os dados foram coletados durante fevereiro a março de 2009, em local com privacidade, e as questôes respondidas pelos próprios entrevistados.

A instituição, cenário da pesquisa, presta atendimento clínico e serviços de Fisioterapia, Nutrição, Psicologia e Serviço Social. É capacitada para prestar atendimento exclusivo aos pacientes com doenças infecto-contagiosas, dentre elas: AIDS (Síndrome da Imunodeficiência Adquirida), tuberculose, hepatite, herpes zoster, meningite, entre outras. Sáo internados pacientes de várias faixas etárias, de ambos os sexos, pelo SUS e, na sua maioria, procedentes de Curitiba e região Metropolitana. A instituição possui um total de 27 leitos com enfermarias conjuntas: 02 enfermarias com 06 leitos e 05 enfermarias com 03 leitos.

\section{Resultados e discussão}

A amostra do estudo foi de 42 pacientes, sendo $45 \%$ da faixa etária entre 30 a 40 anos e 33\% entre 40 a 50 anos, $52 \%$ do sexo masculino e $93 \%$ com diagnóstico HIV (Vírus da Imunodeficiência Humana) positivo.

Tabela I - Opiniões dos entrevistados sobre a admissão no hospital. Curitiba, 2009.

\begin{tabular}{lllll}
\hline Questões & \multicolumn{3}{l}{ Conceitos (\%) } & \\
\cline { 2 - 5 } & Péssimo & Ruim & Bom & Ótimo \\
\hline $\begin{array}{l}\text { Atendimento pela } \\
\text { recepção }\end{array}$ & 0 & 19 & 17 & 64 \\
\hline $\begin{array}{l}\text { Consulta para interna- } \\
\text { mento }\end{array}$ & 0 & 24 & 12 & 64 \\
\hline $\begin{array}{l}\text { Suporte da equipe ao } \\
\text { internamento }\end{array}$ & 0 & 5 & 24 & 71 \\
\hline $\begin{array}{l}\text { Respeito à privacidade } \\
\text { Oportunidade de ex- }\end{array}$ & 2 & 14 & 22 & 50 \\
\hline \begin{tabular}{l} 
pressar sentimentos \\
\hline
\end{tabular} & 12 & 31 & 55 \\
\hline
\end{tabular}

No que se refere ao atendimento na admissão, $60 \%$ considerou ótimo; e com relaçáo à privacidade, $50 \%$ não a consideram plenamente respeitada.

A admissáo é a porta de entrada de um serviço de saúde e é fundamental que o atendimento, a consulta, o suporte da equipe, a privacidade e a expressão de sentimentos sejam valorizados para a continuidade do tratamento ao longo da internação. Em especial, chama a atenção o fato de os pacientes referirem, em $50 \%$ dos casos, a falta de privacidade.

A Cartilha de Ambiência HumanizaSUS (2008) cita que a privacidade diz respeito à proteção da intimidade do paciente, com uso de divisórias ou até mesmo cortinas e elementos móveis, que permitam ao mesmo tempo a integração e a privacidade, facilitando o processo de trabalho, aumentando a interação da equipe e ao mesmo tempo possibilitando o atendimento personalizado [8].

Outro ponto a considerar é a expressão de sentimentos, também referida negativamente por $45 \%$ dos pacientes. É preciso lembrar que se trata da admissão de pessoas com doenças infecto-contagiosas e, na sua maioria (93\%) com AIDS, cuja evolução pode ter conseqüências que levam à morte, sendo assim a recepção e/ou acolhimento precisa, requer e necessita que emoçôes e sentimentos sejam valorizados e respeitados, ou seja, a humanização começa pela recepção. Nesse sentido, a humanização deve iniciar com a chegada do paciente, acompanhante ou visitante ao hospital [9].

Trata-se aqui de qualidade da interação profissional, definida como a capacidade de se criar uma relação de cooperação e o estabelecimento de vínculo entre profissionais de saúde e pacientes para melhores níveis de adesão ao tratamento de doenças. Em estudo, portadores de AIDS relatam sobre a complexidade do tratamento, os efeitos colaterais como náuseas, enjôos e mal-estar, bem como as dificuldades de comunicação entre pacientes e profissionais de saúde. Nestes casos, a postura de acolhimento facilitará o atendimento de demandas específicas e a participaçáo do paciente no planejamento e decisão acerca do seu próprio tratamento [10].

Com relação ao acolhimento dado pelos serviços médicos, de nutrição e serviço social, $11 \%$ dos pacientes, em média, o consideraram entre péssimo e ruim. A relação médico-paciente vem ao longo do tempo sofrendo mudanças e até perdendo algumas 
de suas características fundamentais, como a humanização, a ética e a comunicação.

Gráfico I - Acolhimento pela equipe de saúde do hospital. Curitiba, 2009.

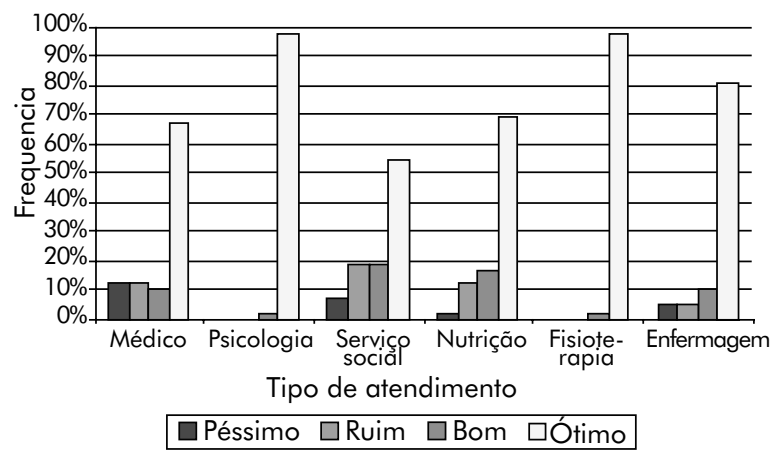

Especificamente sobre o serviço de nutrição, destaca-se que na instituição estudada há quadro reduzido, dificultando assim a inter-relação com os outros profissionais da equipe e com os pacientes. Outro aspecto refere-se à necessidade de dietas especiais que nem sempre agradam aos pacientes, o que repercute na aceitaçáo e estima pelo nutricionista. Já o serviço social tem árdua tarefa nos serviços em saúde, pois nem sempre é possível auxiliar e colaborar com as necessidades sociais de pacientes e familiares.

Talvez se possa inferir que a alta aprovação (98\%) para os serviços de psicologia e fisioterapia se deva ao acolhimento e atenção personalizada que oferecem aos pacientes. $\mathrm{O}$ mesmo ocorre com a equipe de enfermagem, com $80 \%$ dos pacientes considerando ótima.

Diante dos resultados da atuação da equipe multiprofissional, mencionada pelos pacientes portadores de doenças infecto-contagiosas, destaca-se que a complexidade do objeto da saúde exige organização da atenção e envolve distintos profissionais das diversas disciplinas complementares do campo da saúde.

Sendo assim, cabe defender a integralidade como valor a ser sustentado nas práticas dos profissionais, ou seja, um valor que se expressa na forma como os profissionais agem, incluindo sua capacidade de escuta, de forma a permitir a apreensão de necessidades. Ainda, diante de inúmeros problemas de condiçóes de trabalho e ambiente, o desenvolvimento de inovaçóes pautadas por açóes de solidariedade, de cooperação e apoio mútuo tendem a se estabelecer, tornando-se o ponto de partida para renovaçáo dos modelos e práticas de atençáo e cuidado a saúde [11].
Tabela II - Resultados referentes ao conforto dos pacientes nas enfermarias. Curitiba, 2009.

\begin{tabular}{lllll}
\hline Questões & \multicolumn{3}{l}{ Conceitos (\%) } & \\
\cline { 2 - 5 } & Péssimo & Ruim & Bom & Ótimo \\
\hline $\begin{array}{l}\text { Como você considera a } \\
\text { acomodação da enfer- }\end{array}$ & 5 & 10 & 18 & 67 \\
maria & & & \\
\hline $\begin{array}{l}\text { Como considera a roupa } \\
\text { de cama, pijamas, toa- }\end{array}$ & 10 & 10 & 80 \\
$\begin{array}{l}\text { lha de banho do hospital } \\
\text { Como você considera as }\end{array}$ & 0 & 12 & 12 & 76 \\
$\begin{array}{l}\text { refeições } \\
\text { Como você tolera a }\end{array}$ & 5 & 29 & 21 & 45 \\
medicação prescrita & & & & \\
\hline
\end{tabular}

O conforto nas enfermarias foi considerado por $67 \%$ dos entrevistados como ótimo. As refeiçôes são aceitas por $76 \%$, e tidas como ótimas; e $80 \%$ dos entrevistados manifestaram-se de forma positiva em relaçáo às roupas de uso hospitalar. No entanto, a tolerância à medicação obteve $55 \%$ de respostas, o que, provavelmente, significa a presença de efeitos colaterais mais ou menos suportáveis, tais como náuseas, vômitos, diarréia, reaçôes cutâneas, cefaléia, entre outras.

A partir de 1996, com o advento de novas classes de ARV - inibidores da protease e os inibidores de transcriptase reversa não nucleosídios - foi possível alcançar, mediante a terapia anti-retroviral combinada (Highly Active Antiretroviral Therapy HAART), êxitos significativos no tratamento de pessoas infectadas pelo HIV. Contudo, há dificuldades de adesão, pois alguns medicamentos precisam ser ingeridos com alimentos, outros em jejum, ou em seqüências temporais combinadas com outros medicamentos, o que exige organização e compromisso do paciente em relaçáo ao seu tratamento. Em relação à presença de efeitos colaterais, tomar a medicação pode representar uma situação aversiva por causa da ocorrência de conseqüências adversas e desconfortáveis. A ocorrência de lipodistrofia, por exemplo, constitui-se em grande desafio, tanto para as pessoas HIV positivo quanto para as equipes de saúde [10].

Nos esclarecimentos das dúvidas, os profissionais que mais se destacaram foram: psicologia $100 \%$, fisioterapia e nutrição $98 \%$. Os que menos se destacaram, com avaliações péssima e ruim foram: $38 \%$ ao médico, $19 \%$ ao serviço social e $15 \%$ à equipe de enfermagem. 
Tabela III - Dados referentes ao auxílio nas dúvidas por profissionais. Curitiba, 2009.

\begin{tabular}{lllll}
\hline \multirow{2}{*}{ Profissional } & \multicolumn{4}{l}{ Conceitos $(\%)$} \\
\cline { 2 - 5 } & Péssimo & Ruim & Bom & Ótimo \\
\hline Médico & 17 & 21 & 12 & 50 \\
\hline Psicologia & 0 & 0 & 0 & 100 \\
\hline Serviço Social & 7 & 12 & 17 & 64 \\
\hline Nutrição & 0 & 0 & 2 & 98 \\
\hline Fisioterapia & 0 & 0 & 2 & 98 \\
\hline Enfermagem & 10 & 5 & 14 & 71 \\
\hline
\end{tabular}

O trabalho em equipe significa um trabalho conjunto, ou seja, todos falando a mesma língua, todos compreendendo a importância e reconhecendo o papel de cada um, seja médico, enfermeiro, psicólogo, fisioterapeuta, nutricionista, ou outro profissional. Tendo sempre em mente o paciente e suas necessidades, a equipe de saúde poderia colaborar para que as dúvidas destes fossem totalmente esclarecidas, utilizando sempre uma linguagem simples e clara [12].

Com relação à importância da participação da família e/ou amigos no tratamento, 61\% consideram como ótima. Esse resultado reafirma o pressuposto de que a participaçáo de entes queridos reflete positivamente no tratamento de doenças. A inserção da família no tratamento do paciente ajudará e será de fundamental importância no processo de cura ou, em outros casos na compreensão e aceitaçáo de seu estado [12].

Ficar longe da família, dos amigos, do trabalho, foi considerado frustrante e triste por $52 \%$ dos entrevistados; para 45\% ficar muito tempo dentro da enfermaria (no leito) é entediante; e o mau humor dos profissionais aborrece $43 \%$ deles.

Chama a atenção na Tabela IV o fato de $83 \%$ das respostas dos pacientes entrevistados referirem não terem apreensão e medo relacionado à piora ou a morrer no hospital. Supomos que tal situação se deve às suas baixas condiçóes sociais e econômicas, que os levam a considerar o ambiente hospitalar mais seguro e confortável que aqueles em que vivem.

Considerando que $93 \%$ dos entrevistados são doentes de AIDS, destaca-se que segundo a Organização Mundial de Saúde (OMS) o Brasil tem uma epidemia concentrada, com taxa de prevalência da infecção pelo HIV de 0,6\% na população de 15 a 49 anos. De 1980 a junho de 2007 foram notificados 474.273 casos de AIDS no Brasil, sendo 89.250 no Sul, porém os últimos anos são marcados pelo processo de interiorização e pauperização da epide- mia, com mais casos notificados entre as camadas desfavorecidas, com base exclusivamente no fato de haver aumento do número de novos casos de AIDS entre estratos sociais mais pobres, e também dos estratos sociais de maior escolaridade para os menos escolarizados $[13,14]$.

Tabela IV - Opiniões dos entrevistados sobre situações que lhes causam sentimentos de desprazer no ambiente hospitalar. Curitiba, 2009.

\begin{tabular}{lllll}
\hline Questões & \multicolumn{3}{l}{ Conceitos (\%) } \\
\cline { 2 - 5 } & $\begin{array}{l}\text { Intenso } \\
\text { rado }\end{array}$ & $\begin{array}{l}\text { Mode- } \\
\text { reve }\end{array}$ & $\begin{array}{l}\text { Sem } \\
\text { estresse }\end{array}$ \\
\hline $\begin{array}{l}\text { Ficar longe da famí- } \\
\text { lia/amigos/trabalho }\end{array}$ & & 29 & 7 & 12 \\
\hline $\begin{array}{l}\text { Ficar muito tempo } \\
\text { dentro da enferma- }\end{array}$ & 45 & 21 & 14 & 19 \\
$\begin{array}{l}\text { ria (no leito) } \\
\text { A família não poder }\end{array}$ & 29 & 19 & 19 & 33 \\
trazer comida & & & & \\
\hline $\begin{array}{l}\text { Não ter o que fazer } \\
\text { - nenhuma ativi- }\end{array}$ & 24 & 21 & 10 & 45 \\
$\begin{array}{l}\text { dade } \\
\text { Tempo demasia- }\end{array}$ & 26 & 33 & 5 & 36 \\
$\begin{array}{l}\text { do com os outros } \\
\text { doentes }\end{array}$ & & & & \\
\hline $\begin{array}{l}\text { O horário de desli- } \\
\text { gar a TV }\end{array}$ & 19 & 14 & 26 & 40 \\
\hline $\begin{array}{l}\text { Mau humor dos } \\
\text { profissionais }\end{array}$ & 43 & 29 & 12 & 17 \\
\hline $\begin{array}{l}\text { Piora ou morte de } \\
\text { um doente }\end{array}$ & 26 & 17 & 10 & 48 \\
\hline $\begin{array}{l}\text { Piorar e, ou morrer } \\
\text { no hospital }\end{array}$ & 0 & 0 & & \\
\hline & & & & \\
\hline
\end{tabular}

Diante deste cenário de epidemia, a presença solidária do profissional, refletida na compreensão e no olhar sensível, que desperta sentimento de confiança e solidariedade, pode criar uma rede de construção permanente de laços de cidadania, de um modo de perceber cada sujeito em sua especificidade, sua história de vida, mas também de olhá-lo como sujeito de um coletivo, sujeito da história de muitas vidas [15].

Em relação às outras questóes da mesma tabela, a intensidade do desprazer é visível e preocupante; trata-se de situaçóes comuns em ambiente hospitalar, no entanto a humanização tem requerido que se procure minimizar ao máximo as condiçóes que levam o paciente ao sofrimento. Algumas sugestóes para minimizar poderiam ser: ampliar o horário de visitas; estimular aqueles que podem sair do leito 
a deambular até o pátio; orientar os pacientes e familiares sobre os riscos de alimentos vindos de fora; solicitar atividades com a terapia ocupacional e musicoterapia, para diminuir o tempo ocioso e promover açóes educativas e recreativas; isolar os pacientes terminais e, em caso de falecimento, reunir os pacientes e conversar sobre o fato ocorrido.

Tabela V - Dados sobre as atividades dos pacientes para ocupar o tempo ocioso. Curitiba, 2009.

\begin{tabular}{ll}
\hline Tipo de atividade & $\%$ \\
\hline Permanece no leito & 57 \\
Anda no pátio & 31 \\
Assiste à TV & 17 \\
Conversa & 17 \\
Fuma & 17 \\
Dorme & 14 \\
Lê & 14 \\
Outros & 12 \\
\hline
\end{tabular}

Os dados obtidos sobre atividades desenvolvidas para ocupar o tempo ocioso revelam que 57\% dos entrevistados permanecem no leito e $31 \%$ dos que deambulam sem dificuldades andam no pátio - quando autorizados.

Essa tabela mostra quão pequena são as oportunidades e as opçóes aos pacientes de ocupar seu tempo. São atividades monótonas e provavelmente bem repetitivas. Talvez fosse importante rever essa situação, considerando que o tempo de internamento na instituição pode ser longo, acrescido do agravamento da doença.

O fato de o paciente ficar muito tempo no leito pode agravar sua condição física e psicológica. Oportunizar jogos (recreaçóes), trabalhos manuais, artesanais, realizados preferencialmente na parte externa do hospital (pátio), poderia ajudar significativamente no seu estado emocional. Como $31 \%$ apreciam andar no pátio, esta seria uma boa oportunidade de realizar açóes de socialização, inclusive com os familiares.

Ainda, na entrevista, $67 \%$ dos pacientes referiram que o tempo ocioso interfere na sua recuperação. Entendemos que o ambiente de internaçáo requer silêncio, repouso, tranqüilidade, no entanto precisa haver equilíbrio para que náo se torne restritivo e entediante. Talvez se pudesse, em outro estudo, coletar informaçóes junto aos pacientes sobre as maneiras, estratégias e açóes que poderiam ocupar o seu tempo sem riscos à sua saúde e seu bem estar.
Tabela VI - Formas que o tempo ocioso afeta a recuperação. Curitiba, 2009.

\begin{tabular}{ll}
\hline Forma de afetar a recuperação & $\%$ \\
\hline Provoca ansiedade/angústia & 24 \\
Desejo de fumar mais & 10 \\
Preocupação com a doença e recuperação & 10 \\
Maior irritação & 5 \\
Sensação que o tempo não passa & 5 \\
\hline
\end{tabular}

Para 24\% dos entrevistados o tempo ocioso provoca ansiedade/angústia; para $10 \%$, mais vontade de fumar, como também maior preocupação com a doença e a sua recuperação; para $5 \%$ provoca irritabilidade mais acentuada e sensação de tempo que não passa.

Cabe, nesta situaçáo, a participação da equipe de saúde contribuindo com o enfrentamento da doença, com reforços positivos e criativos que auxiliam sobremaneira a vontade, a determinação e a segurança de pacientes. Estudo sobre qualidade de vida de pacientes com AIDS mostra que o caráter de cronicidade prevê o seguimento a longo prazo e acarreta a necessidade de avaliação e acompanhamento dos aspectos psicossociais. Como tal é preciso subsidiar continuamente a estruturação de serviços com a associação entre disponibilidade e satisfação com o suporte social, bem-estar psicológico, percepção positiva de vida e atendimento seguro de demandas médicas evitando o isolamento social, a restriçáo dos relacionamentos interpessoais e as dificuldades no campo afetivo que possam surgir no contexto de vida dessas pessoas [16].

Os dados da pesquisa revelam ainda que $73 \%$ dos entrevistados náo têm queixas com relaçáo aos ruídos e para $27 \%$ os ruídos causados precisam ser suavizados, pois estes são contínuos e diuturnos, como exemplo o ruído da lavanderia, com seus maquinários e centrífugas.

Ruídos em ambiente de trabalho são comuns, no entanto seria prudente cuidar com o volume, pois em especial a instituição em estudo é construção antiga, na qual os ruídos fazem eco e soam mais alto pela altura e largura de corredores e quartos.

Estudos têm mostrado que a equipe hospitalar deve estar consciente do ruído e dos efeitos deste, para que possa atuar de maneira mais efetiva na redução da poluição sonora, beneficiando assim a função laborativa dos profissionais e recuperação dos pacientes. Embora sejam muitas as fontes produtoras de ruído excessivo, estas precisam ser melhor identificadas para que possam ser tomadas as devidas 
medidas para atenuação desse ruído e tornar esse ambiente um local mais silencioso $[17,18]$.

\section{Conclusão}

O trabalho objetivou identificar e interpretar as possíveis situaçóes de ambiente e de inter-relaçóes que interferem no tratamento do paciente com doenças infecto-contagiosas. Os resultados apontaram para o fato de haver pouca atividade educativa ou lúdica na instituição, considerando que são pacientes que têm períodos longos de internação.

Compreender estas atividades em ambiente hospitalar propiciariam estratégias de implementação de espaço mais adequado e agradável. Nesse sentido, os resultados deste estudo seráo apresentados à direçáo do hospital, com sugestóes de como aproveitar o tempo livre dos pacientes com o desenvolvimento de açôes de musicoterapia e terapia ocupacional. Pretende-se, também, que os pacientes participem ativamente do processo de seleçáo de atividades, pois devem se sentir envolvidos.

A busca de soluçóes às situaçóes que tornem o ambiente o mais agradável possível é contínua; afinal não conhecê-las dificulta a atuação profissional específica, que é a chave para a humanização, favorecendo também a melhor evolução do paciente. Nesse mesmo alinhamento, os entrevistados sentemse bem na presença da família, logo, percebe-se a necessidade do envolvimento desse grupo social por meio de assistência educacional, imprescindível na determinação do equilíbrio físico e mental dos pacientes.

Por fim, é de responsabilidade da gestão de serviços de saúde hospitalar a criaçáo de condiçóes que respeitem o direito das pessoas a um ambiente humano propício a viver com dignidade, aos profissionais cabe a solidariedade e sensibilidade de atuar de maneira digna, respeitando seus direitos em assistência humanizada e ética.

\section{Referências}

1. Bess d'Alcântara E. Criança hospitalizada: o impacto do ambiente hospitalar no seu equilíbrio emocional. Psicópio: Revista Virtual de Psicologia Hospitalar e da Saúde 2008;6(3):38-55.

2. Ministério da Saúde. AIDS no Brasil. AIDS em números. Brasília: Ministério da Saúde; 2007.

3. Ministério da Saúde. Programa Nacional de Humanização da Assistência Hospitalar - PNHAH. Secretaria de Assistência à Saúde. Brasília: Ministério da Saúde; 2001.

4. Angerami-Camon VA. O doente a psicologia e o hospital. São Paulo: Pioneira; 2001.

5. Backes DS, Lunardi VL, Lunardi Filho WD. A humanização hospitalar como expressão ética. Rev Latinoam Enfermagem 2006;14(1):132-5.

6. Oliveira LA, Landroni MAS, Silva NEK, Ayres JRCM. Humanização e cuidado: a experiência da equipe de um serviço de DST/Aids no município de São Paulo. Ciênc Saúde Coletiva 2005;10(3):689-98.

7. Backes DS. A construção de um espaço dialógicoreflexivo, no contexto interdisciplinar, com vistas à humanização do ambiente hospitalar. Texto \& Contexto Enferm 2005;14(3):435-6.

8. Ministério da Saúde. Cartilha de ambiência - HumanizaSUS. Brasília: Ministério da Saúde; 2008.

9. Dias NM. Humanização hospitalar: a atenção à recepção. Psicópio: Revista Virtual de Psicologia Hospitalar e da Saúde 2007;3(6):30-7.

10. Seidl EMF, Melchíades A, Farias V, Brito A. Pessoas vivendo com HIV/AIDS: variáveis associadas à adesão ao tratamento anti-retroviral. Cad Saúde Pública 2007;23(10):2305-16.

11. Costa AM. Integralidade na atenção e no cuidado a saúde. Saúde Soc 2004;13(3):5-15.

12. Fones AFPN. Propostas para uma melhor adaptação do paciente ao meio hospitalar. Psicópio: Revista Virtual de Psicologia Hospitalar e da Saúde 2009;4(8):12-7.

13. Ministério da Saúde. AIDS no Brasil. Brasília: Ministério da Saúde; 2007.

14. Bastos FI, Szwarcwald CL. AIDS e pauperização: principais conceitos e evidências empíricas. Cad Saúde Pública 2000;16(1):65-76.

15. Mota RA, Martins CGM, Veras RM. Papel dos profissionais de saúde na política de humanização hospitalar. Psicol Estud 2006;11(2):323-30.

16. Seidl EMF, Zannon CMLC, Troccoli BT. Pessoas vivendo com HIV/AIDS: enfrentamento, suporte social e qualidade de vida. Psicol Reflex Crit 2005;18(2): 188-95.

17. Otenio MH, Cremer E, Claro EMT. Intensidade de ruído em hospital de 222 leitos na 18a Regional de Saúde - PR. Rev Bras Otorrinolaringol 2007;73(2):245-50.

18. Pereira RP, Toledo RN, Amaral JLG. Qualificação e quantificação da exposição sonora ambiental em uma unidade de terapia intensiva geral. Rev Bras Otorrinolaringol 2003;69(6):766-71. 